\title{
A Java based University Library Management System
}

\author{
Asaduzzaman Noor \\ Programmer \\ Integrated Software Development Team \\ Southeast University, Bangladesh
}

\author{
Md. Sharif Hossen \\ Lecturer \\ Department of Information and Communication \\ Technology \\ Comilla University, Bangladesh
}

\begin{abstract}
In the era of modernization, everything is accomplished or thought to be accessed through internet so that do not need to waste time and face any inconvenience. Using internet, the democratization of knowledge has been easier. The concept of sharing knowledge is centralized in a digital library, which plays a vital role in the dissemination of knowledge and spiritual civilization. The level of maintaining a library is closely related to the quality of teaching in Universities. With the increasing of number of students in Universities, maintaining a library using the old management methods is too much complex and time consuming and hardly possible to adapt to the development of times. To overcome this situation appeared in most of the middle level countries like Bangladesh, authors develop an automated digital library management system. The main features of this software are user interactive graphical representation (using bar diagram and pie chart) of the total number of books requested, books uploaded, yearly books count etc. Besides, notifications and reports are viewed instantly for corresponding users. Another thing is that using this software, user could find out books searching by any one of these: title, author's name, subject, publication, series, ISBN/ISSN, etc. That is, the developed automated library management software would meet the needs of the growing students and teachers demand.
\end{abstract}

\section{Keywords}

Library management system; Application; Software; Java

\section{INTRODUCTION}

In most universities, there are well-equipped libraries with excellent infrastructure facilities having a large collection of books. Compared to public libraries, university libraries have a large collection on science and engineering where readers get scope for gathering vast knowledge on respective fields. Because of the dispersion of knowledge, this collection increases rapidly day by day [1]. Although there are many existing software tools, most of those are not proper user interactive and have some limitations for accessing the books. Besides, most universities in mid-level countries like Bangladesh still are using traditional way to manage their library, which prevents faster searching for a book, and faster report generation. This leads to develop an online digital library management system [2]. A good interactive interface was available and users could obtain a fresh and different feeling [3]. Proper security has been maintained in the proposed system because only authorized users could access this application by doing the registration. Users need to have online connection and an email account [4] to register and use this software.

Library management system has three modules, which are Admin Module, Librarian Module, and Student Module. First module assists administrator to register shelf and category, change book status, issue library card, configure to registered users, and backup database. Second module helps students to find out books by searching by title, author's name, subject, publication, series, ISBN/ISSN, etc. In the last module, librarian can issue and fine for books received after due date. The developed library management system has a nice functionality to upload and download online book and resources. From this library management system, any educational institute can easily set all required library settings like as late fee amount, maximum borrowed books, maximum borrowed time etc. Besides, the system will auto generate students late fee, book availability, book place, top books etc.

Another important feature is to provide portability of the software. This feature indicates, "write once" and "run anywhere" of the application on multiple platforms [5]. In the development of this software, Java is used as the development tool considering its various advantages [6], [7], [8], e.g., platform independence, polymorphism, automatic garbage collection etc. Hence, NetBeans IDE is used with version 8.2 [9]. Besides, authors use MySQL database server and FTP (File Transfer Protocol) server for storing data and transferring files respectively.

Using this software, librarian could easily generate reports and take quick decisions on any transaction of books about the availability of resources [10]. The rest of this paper is structured as follows. Section 2 shows the database design including relationship schema. Section 3 presents the systematic procedures to setup and run this application. In Section 4, conclusions and future works are presented.

\section{DATABASE DESIGN}

In this software development, MySQL is used as the database server. A database is a collection of interrelated data stored with minimum redundancy to serve many users quickly and effectively. The general objective is to make information access easy, quick, inexpensive and flexible for performing overall all operations by users. In addition, following considerations are taken during the development: controlled redundancy, data independence, accuracy, and integrating more information at low cost, recovery from failure, privacy and security, performance ease of learning and use [11].

Figure 1 describes the use case of user's roles. There are three types of users, namely, Admin, Librarian and Student. Admin can add, edit and view the librarian. He/she can see academic setting and update MySQL database, FTP (File Transfer Protocol) details. He is able to generate the full database backup and able to update admin and librarian's password. Librarian can add, edit and modify Students and Books related tasks. He is able to manage borrowers and book's transaction. Students are able to view and search books to borrow. The overall process of this software tools is shown in the following diagram, which describes the functionality of each user. 


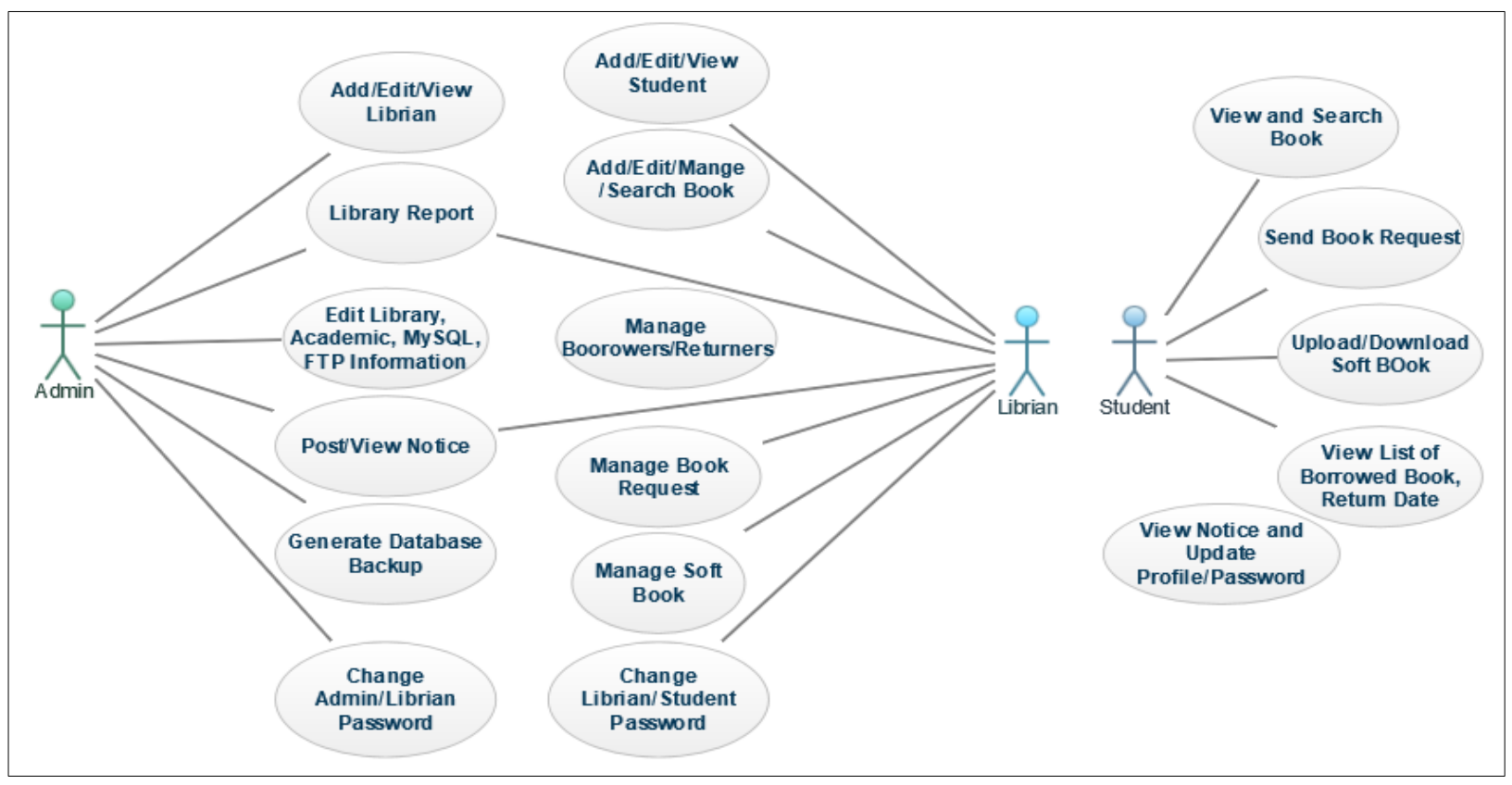

Fig. 1. Use Case Diagram

Figure 2 describes the relationship schema of the library management system. Here, the tables 'library_student', 'library_librarian', and 'book_collection' contain respectively the details of the students, the librarians, and the books. Similarly, the details of the requested, newly uploaded, and borrowed books are stored respectively in the tables, namely, 'book_request', 'soft_book', and 'borrow_list'. Besides, the details of each transaction, notification and notices updated by admin or librarian are stored respectively in 'transaction_history', 'notification', and 'notice' tables. Finally, the settings related information are stored in 'library_settings' table.

\begin{tabular}{|c|c|c|c|}
\hline book_reques & library_student & soft_book & library librariar \\
\hline id & name & \begin{tabular}{|l} 
id \\
bookName \\
\end{tabular} & name \\
\hline name & $\begin{array}{l}\text { NickName } \\
\text { studentlD }\end{array}$ & \begin{tabular}{|l} 
bookName \\
authorName
\end{tabular} & NickName \\
\hline \begin{tabular}{|l} 
batch \\
dept
\end{tabular} & $\begin{array}{l}\text { studentID } \\
\text { password }\end{array}$ & $\begin{array}{l}\text { authorName } \\
\text { edition } \\
\end{array}$ & username \\
\hline bookTitle & email & bookDesc & password \\
\hline authorName & batch & uploaderName & email \\
\hline edition & department & uploaderiD & \\
\hline status & DOB & uploaderDept & \\
\hline requestDate & $\operatorname{sex}$ & bookPath & book_collection \\
\hline lastupdate & Blood & uploadDate & accession \\
\hline & Religion & lastupdate & clAccession \\
\hline & MaritalStatus & status & isbn \\
\hline & Occupation & & bookTitle \\
\hline notification & HomeDistrict & & authorName \\
\hline id & Citizenship & & edition \\
\hline notificationFrom & HomeMailingAddress & borrow_list & bookself \\
\hline notificationTo & PermanentAddress & studentlD & row \\
\hline notificationMesage & contact & studentName & columnNo \\
\hline notificationstatus & status & studentBatch & availability \\
\hline & image & studentDept & borrowedTime \\
\hline & joinedYear & bookAccession & bookAddedYear \\
\hline notice & & booklsbn & \\
\hline Serial & & borrowDate & \\
\hline \begin{tabular}{|l|} 
NoticeFrom \\
\end{tabular} & & returnDate & \\
\hline \begin{tabular}{|l|} 
Postedon \\
\end{tabular} & & & \\
\hline \begin{tabular}{|l|} 
Title \\
\end{tabular} & & & \\
\hline Details & library_setting: & & \\
\hline & latefee & id & \\
\hline & borrows_time & name & \\
\hline & maxBook & accession & \\
\hline & bookRequ & isbn & \\
\hline & \begin{tabular}{|l} 
uploadRequ \\
\end{tabular} & date & \\
\hline & & \begin{tabular}{|l|} 
type \\
latefee
\end{tabular} & \\
\hline
\end{tabular}

Fig. 2. Relationship Schema

\section{IMPLEMENTATION}

In this library management system, there are three types of users' roles: Admin, Librarian and Student. Here, Admin is the main role of this system who can set up the main function. Then librarian can manage books and students. Finally, students can access to see book information and track their borrowed books, etc.

\subsection{Admin Module}

At the beginning of this application, system will show the login page as shown in Figures 3 and 4. Here, firstly, the system needs the academic information like as academic name, address, phone, email, logo, holder name and a unique name (as shown in Figure 3). Secondly, few steps for MySQL database connection, FTP, and messenger details are required (not shown here). Finally, the 
system will ask for a license key, software status (available for other users or not) and demo data (to test the software) which is shown in Figure 4. If all the information are correctly given, then it will install the software and create a configuration file in a directory. Then, the system will automatically send a confirmation email with the institution's unique name and admin password.

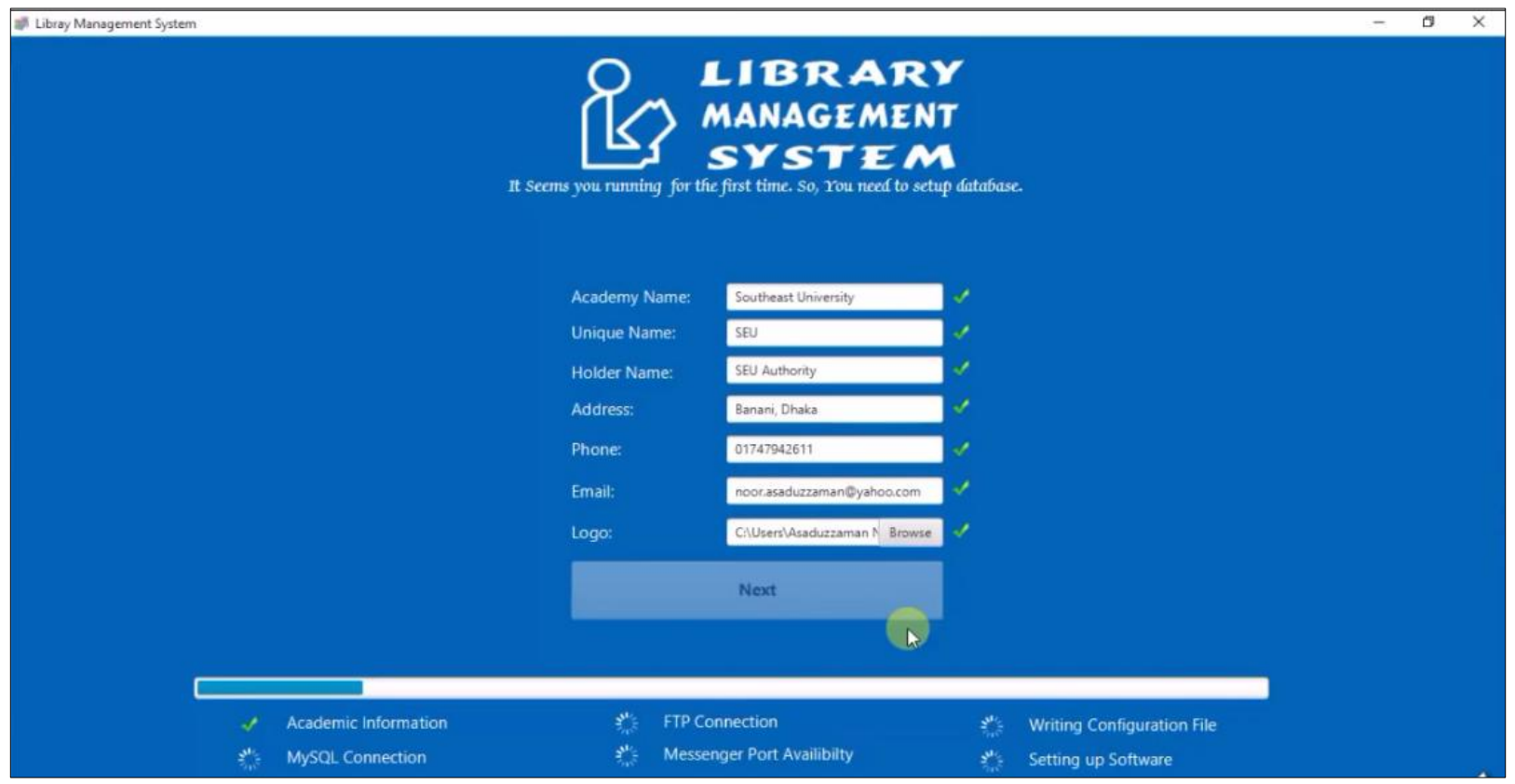

Fig. 3. Installation Phase I

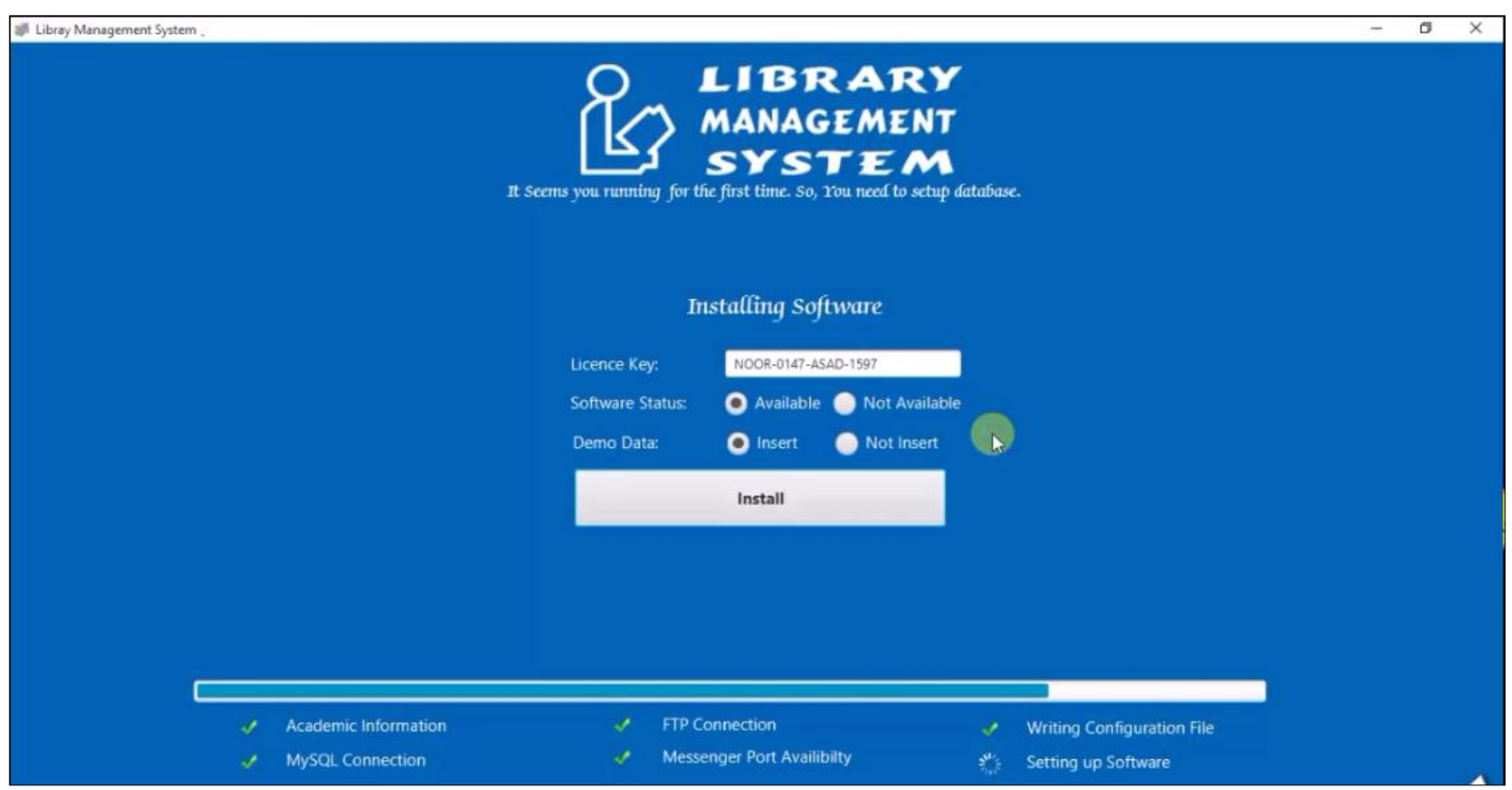

Fig. 4. Installation Phase II

After successful connection, login panel will be appeared, where unique name and password are required (not shown here to make short). A user could change the password later. If login credentials are correct, then admin home page (as shown in
Figure 5) will be appeared. From right options panel, a user can choose admin option. There are also six kinds of themes featured for outlooking. 


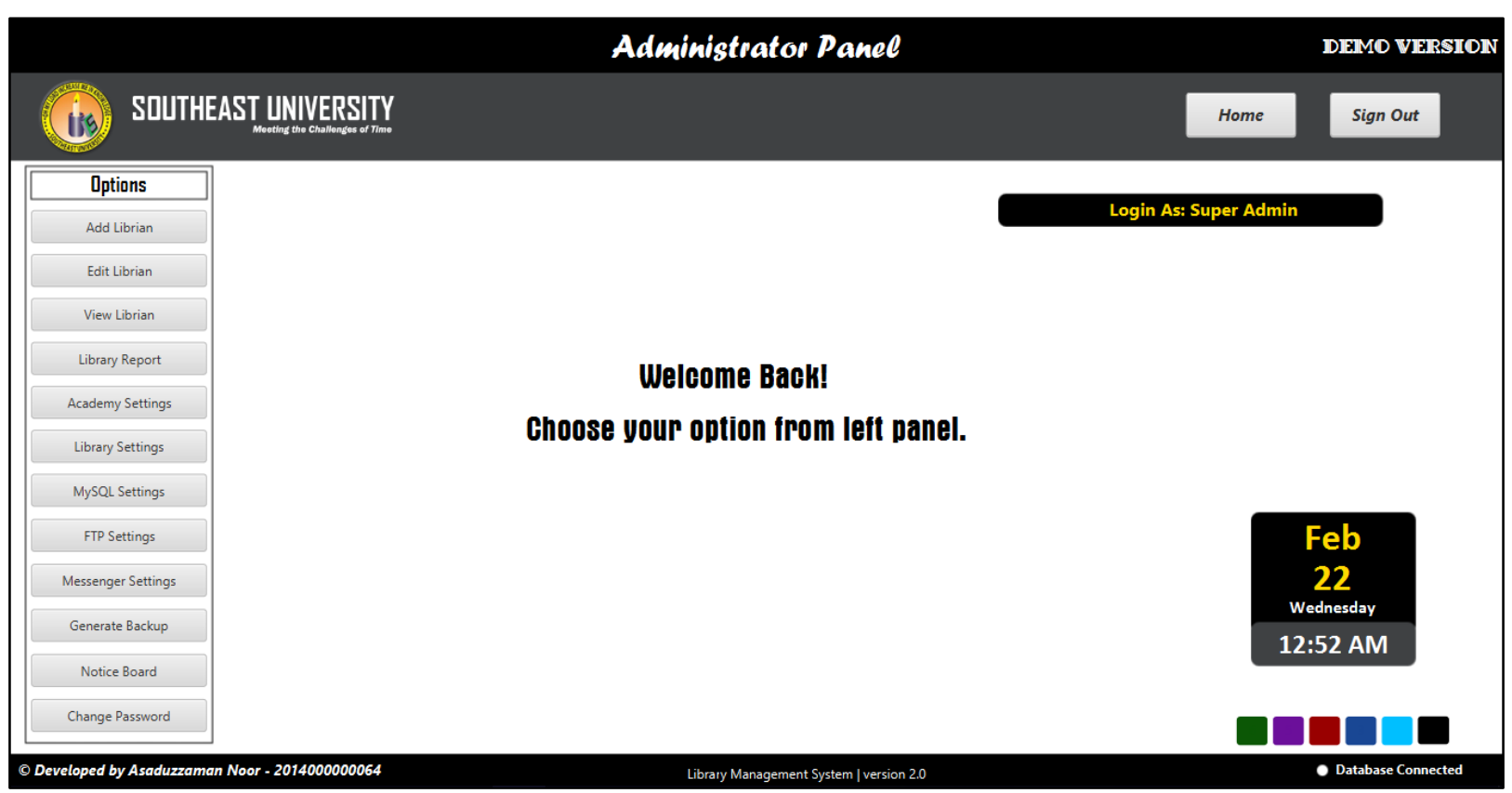

\section{Fig. 5. Admin Home Page}

In the right options of the above figure, Admin can add a new librarian, edit existing librarian profile and password, and see librarian details. In the Library Report section, a user can see graphical representation of the summary of library, where pie charts show book request and upload statistics while histogram shows Book Count and Student Count statistics depending on year as shown in Figure 6 .

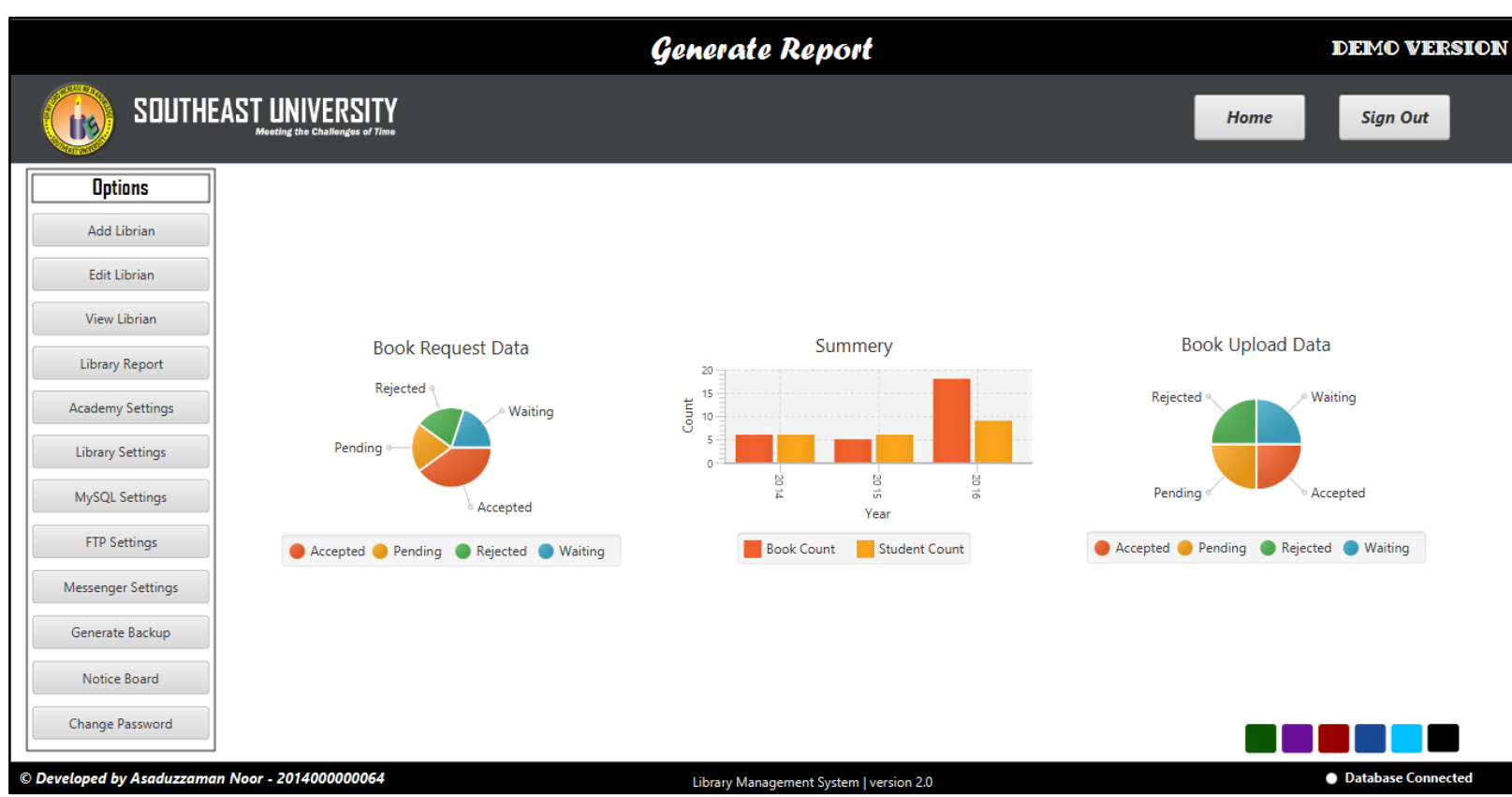

Fig. 6. Library Home Page and Statistical Reports

In addition, admin can update academic information with logo using Academic Settings section, which can change automatically for all users as shown in Figure 7. In Library Settings section, admin can update library rules like as late fee amount, maximum borrowed book count, book borrowed time, maximum uploaded books, and request at a time count. Admin can also change MySQL database location, FTP information, messenger activation. Full database can be backup into a SQL file using Generate Backup section. All kinds of notice can be found in Notice Board section. Password can also be changed. 


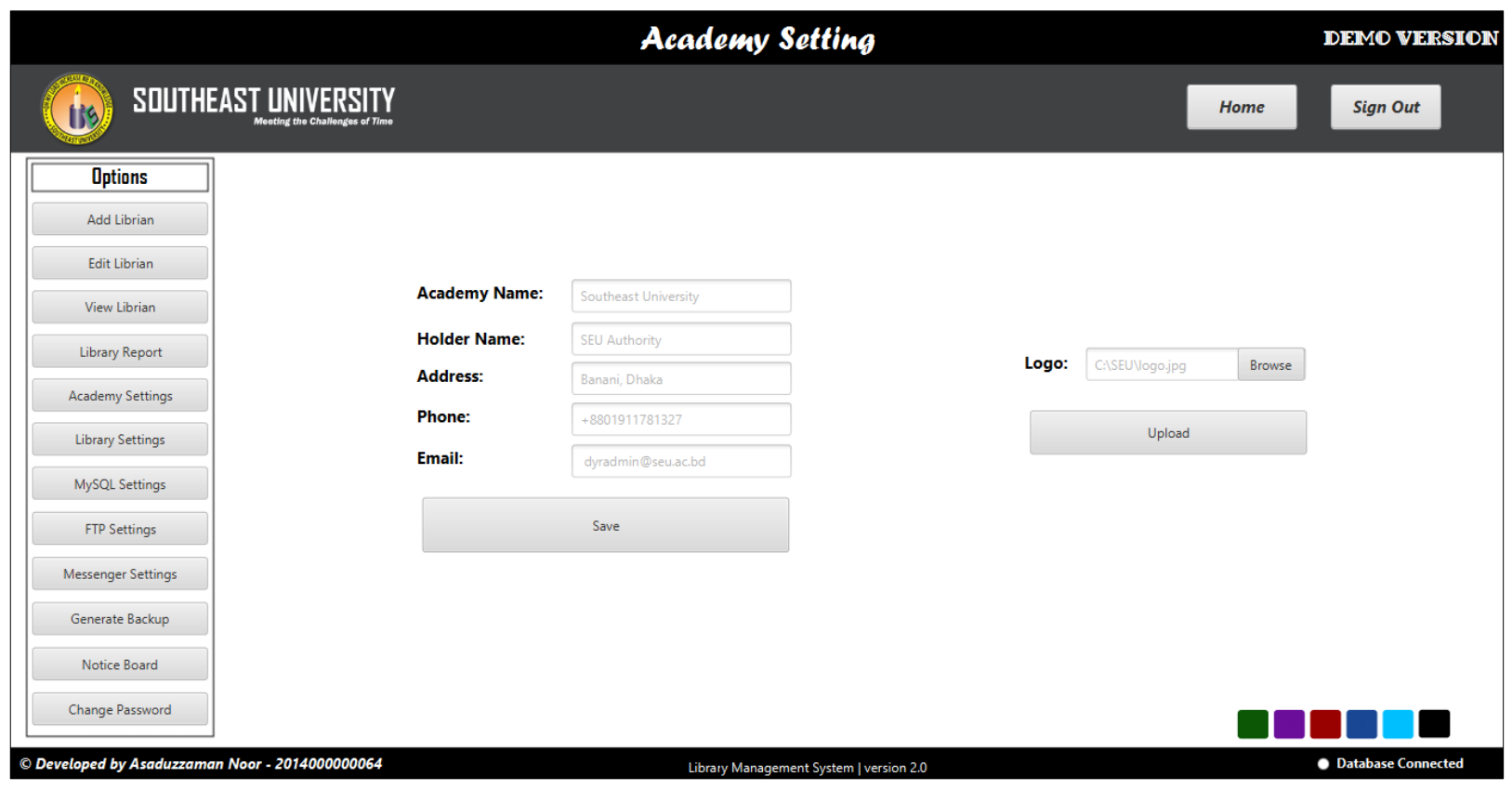

\subsection{Librarian Module}

Fig. 7. Academic Setting

In this case, user as a librarian need to select the institution unique name and press install button. Then librarian will login with the username and password in login panel (not shown here).

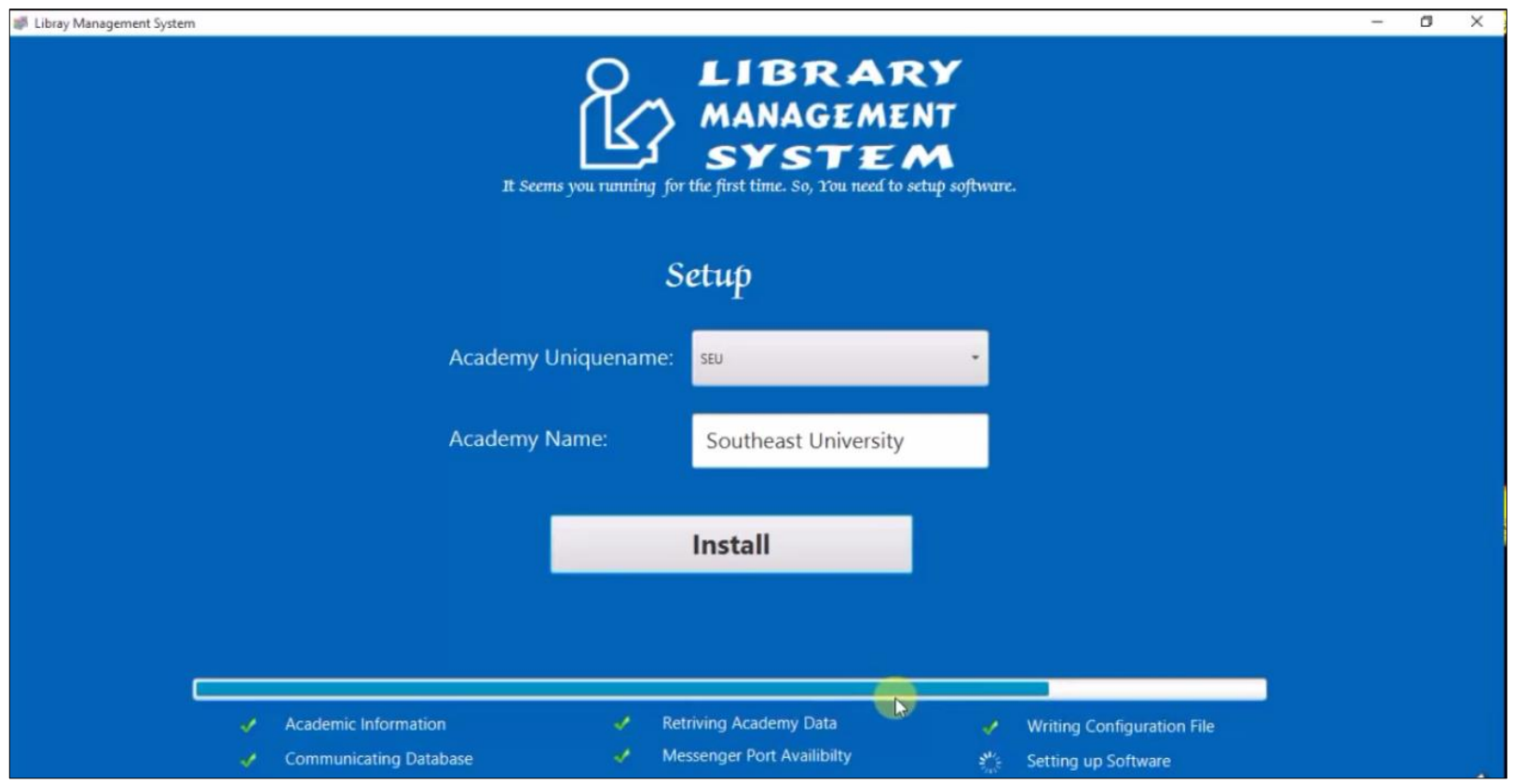

Fig. 8. Librarian Installation

If login credentials are correct in Figure 8, then the librarians' home page will be appeared as shown in Figure 9. He can choose admin option where a summary of library statistics and notifications about books and notice will be shown. 


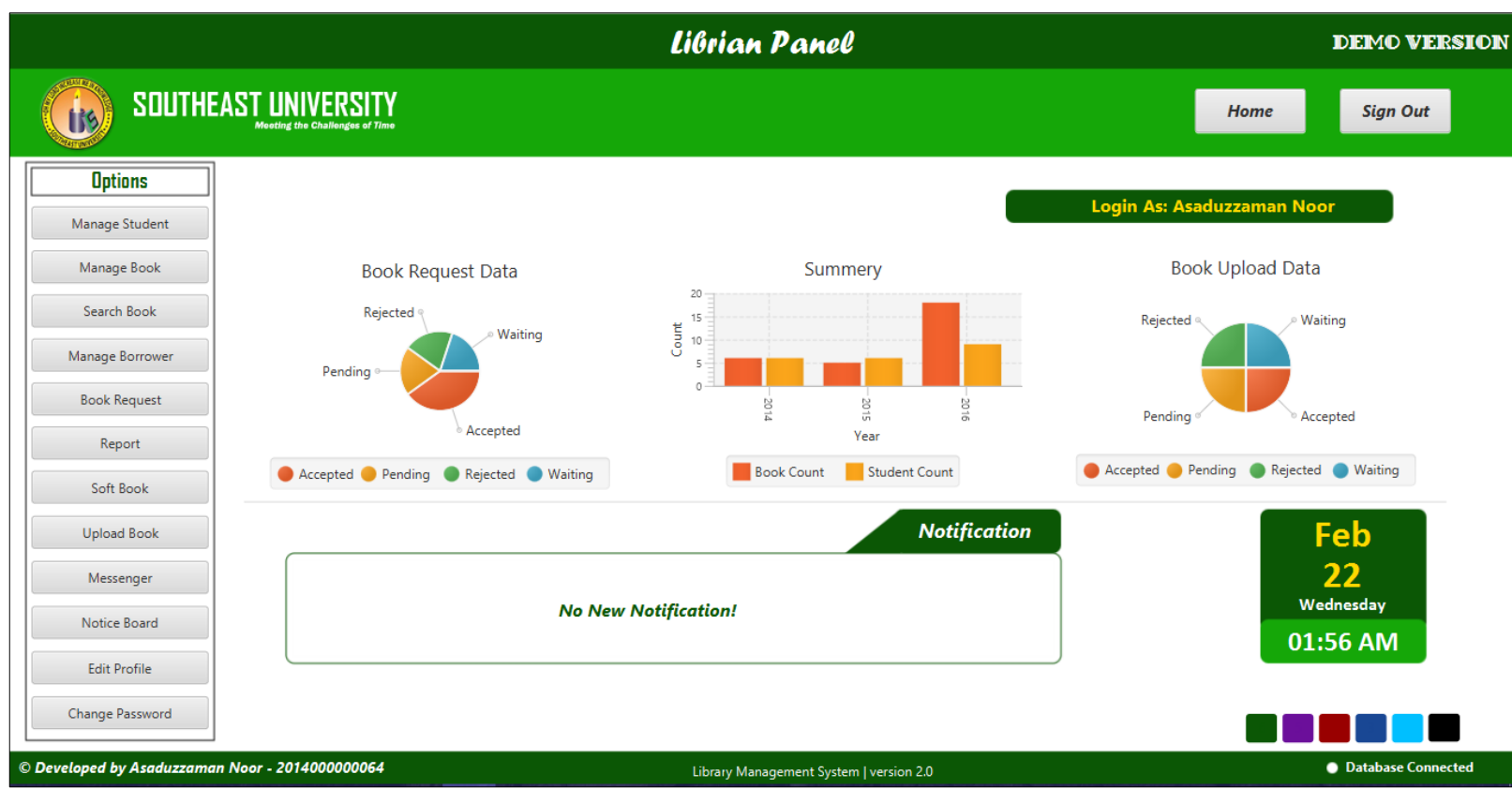

Fig. 9. Librarian Panel

In Manage Student section, there are 3-tabs namely, 'Add Student', 'Edit Student' and 'Student Details'. From 'Add Student' tab, a new user can be added. If all information is valid, then a new student will be added into database. From 'Student Details' tab, an existing user profile will be shown. Librarian can be also set as Active/Inactive. If a student is set as inactive, then this student cannot borrow book, upload and request for books. A warning will be shown in student's profile and student's main page. From 'Edit Student' tab, an existing user profile can be edited. If all the information are valid, then user profile will be updated.

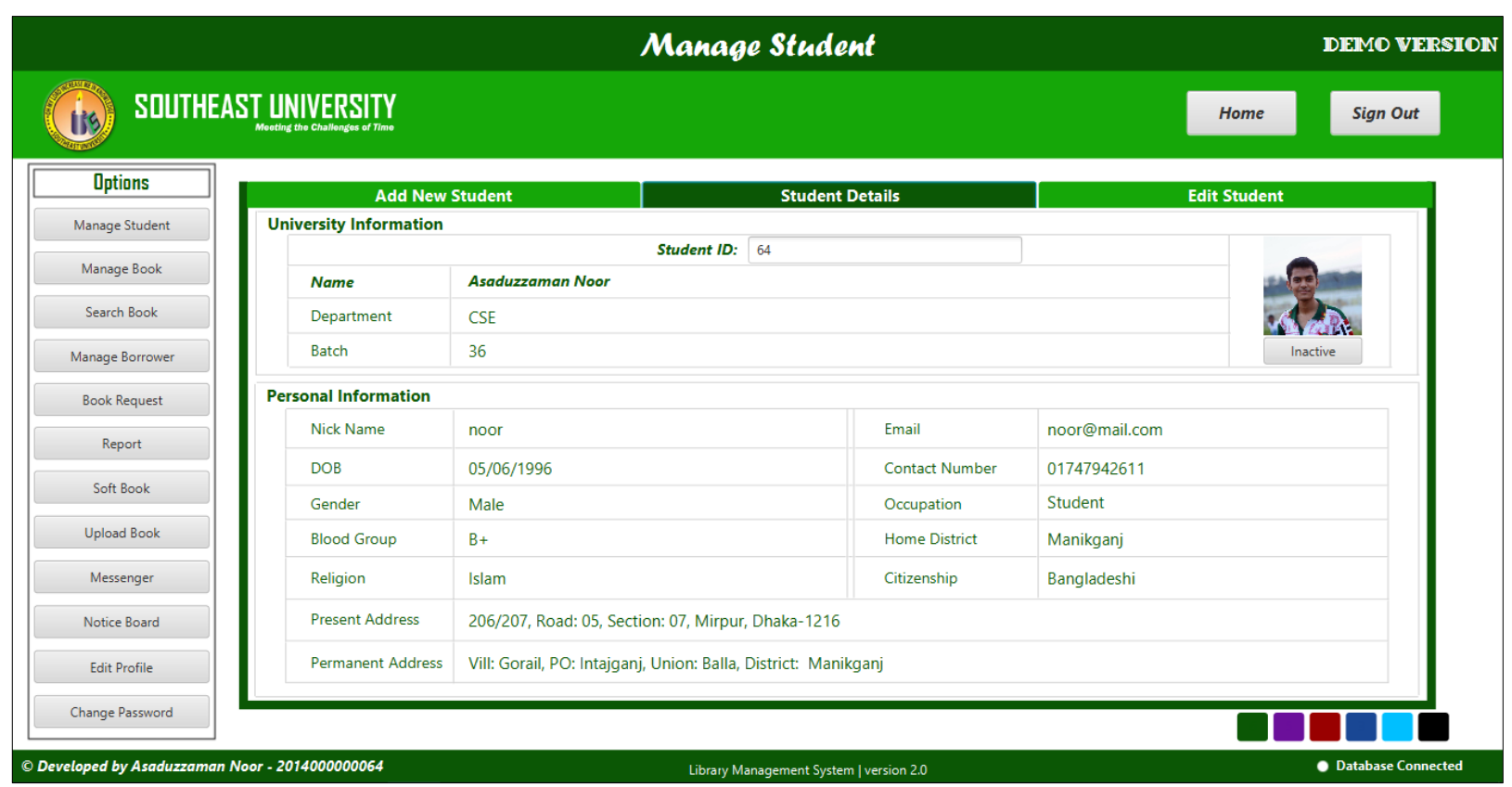

Fig. 10. Managing Student

In Manage Book section, there are also 3-tab panes, namely, 'Add New Book', 'Edit Book' and 'List of Books'. Using 'Add New Book' tab, a new book can be added. Here, Accession number is a book id, which is unique. ISBN number is also unique for each books. If an ISBN already added, then Book Title, Author, Edition will automatically be shown. Otherwise, all the information can be added. Book location can also be added, which helps to find the book location easily. Book availability in the library is easily informed to users. The status, Reserve Book means this book is available in library but cannot be borrowed.
From 'List of books' tab, all book information will be appeared in a table. Using 'Edit Book' tab, an existing book including all information can be updated. If all the information are valid, then it will update book information. In Search Book section, there are also 3-tab panes for searching books in different categories, namely 'Search by Accession Number', 'Search by ISBN', and 'Search by Book Name' for searching books by using accession number, ISBN, and book names respectively. In Manage Borrower section, 3-tab panes are 'Borrow Book', 'Borrower List', and 'Return Book'. In Book Request section, librarian can 
see the books, which students want to read. Librarian can also change the status of this request. In Report option, a librarian can generate report in three different categories for Students, Books and Transactions as shown in Figure 11. In Soft Book option, a librarian can see the list of soft book uploaded in the server. In Upload Book option, a librarian can upload soft book into server. In addition, he/she can accept, reject or pending uploaded soft book by students. From Messenger option, a librarian can communicate with another librarian if online. There needs to run another software for running messenger as a server. Notice Board is similar to Admin Panel. Here, Librarian also can post and view notices posted by admin and librarian. Librarian can update own profile in Edit Profile section and change own password or student's password on request.

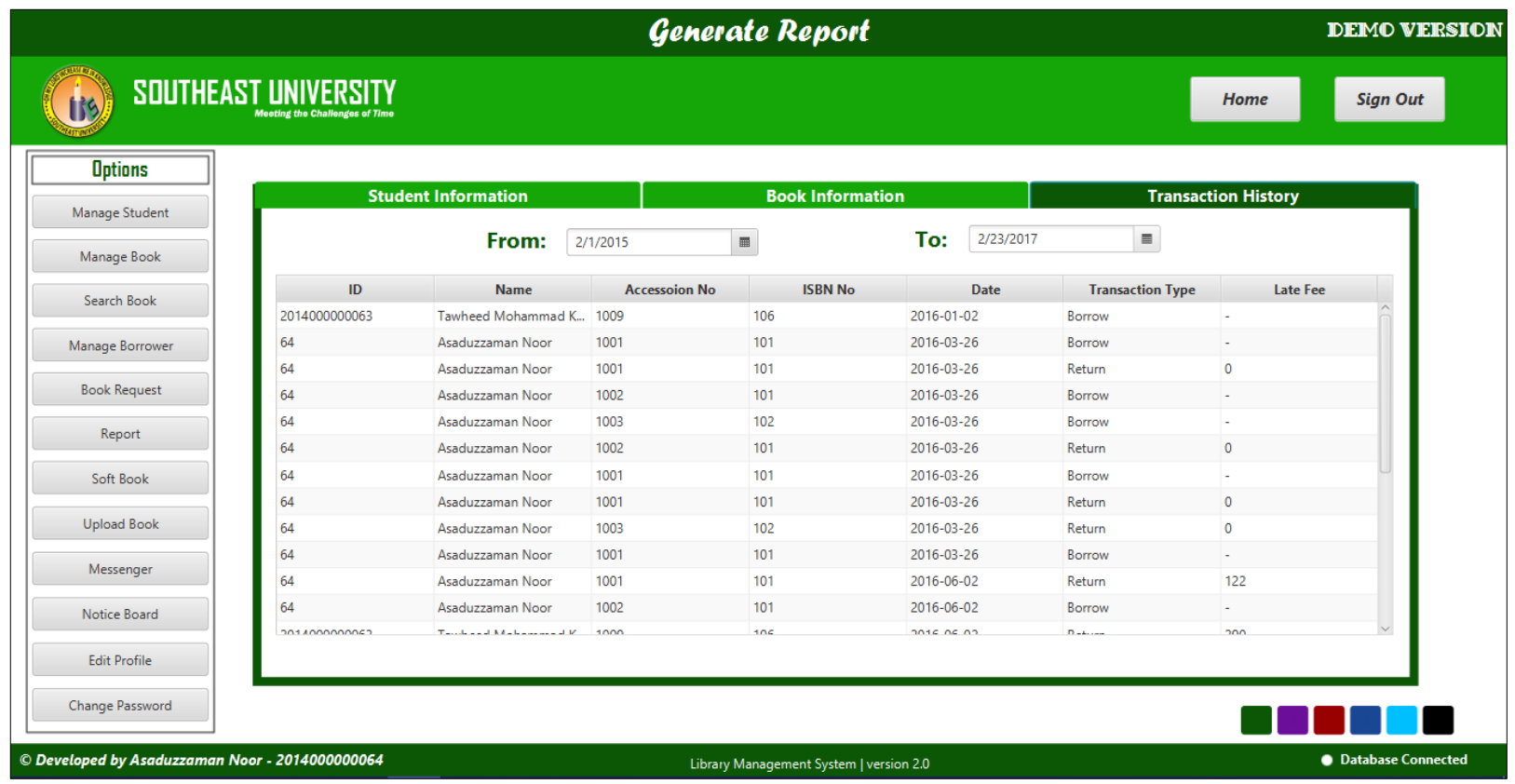

Fig. 11. Report Panel

\subsection{Student}

To maintain the role of a student, first a user needs to install this management system in student mood. If login credentials are correct, then student's home page as shown in Figure 12 will be appeared. From right panel, a user choose admin option where a summary of the library statistics and notifications about books and notices will be shown. Here, students can see their profile information, all book list with book information, and search books. Borrow List section will show the list of books which borrowed by login user. Book Request section has two tabs, one is for adding the book request and other is for book request list. In 'Add Request', student can add the book request, which needs to add in library. In 'Your Request' tab, students can see the requests sent and their status. In Report option, students can generate reports in three different categories for Book, Book
Transaction and top three books. Book Report is similar to librarian, where all book information can be generated. In addition, it is possible to add ISBN and BookShelf wise filter. In Tansaction History, students can generate date wise transaction of books with details for login user. In 'Most Borrowed Book' tab, students can see the top three books, which are borrowing most. In Soft Book option, student can see the list of soft book uploaded in server by this student. In Upload Book option, student can upload soft book into server, which needs for approval of librarian for showing into all student list. From Messenger option, students can communicate with each other on online as shown in Figure 13. From View Notice, students can see the notice posted by admin and librarian. In Edit Profile, students can edit their own profiles. Students can update their own passwords using Change Password option. 


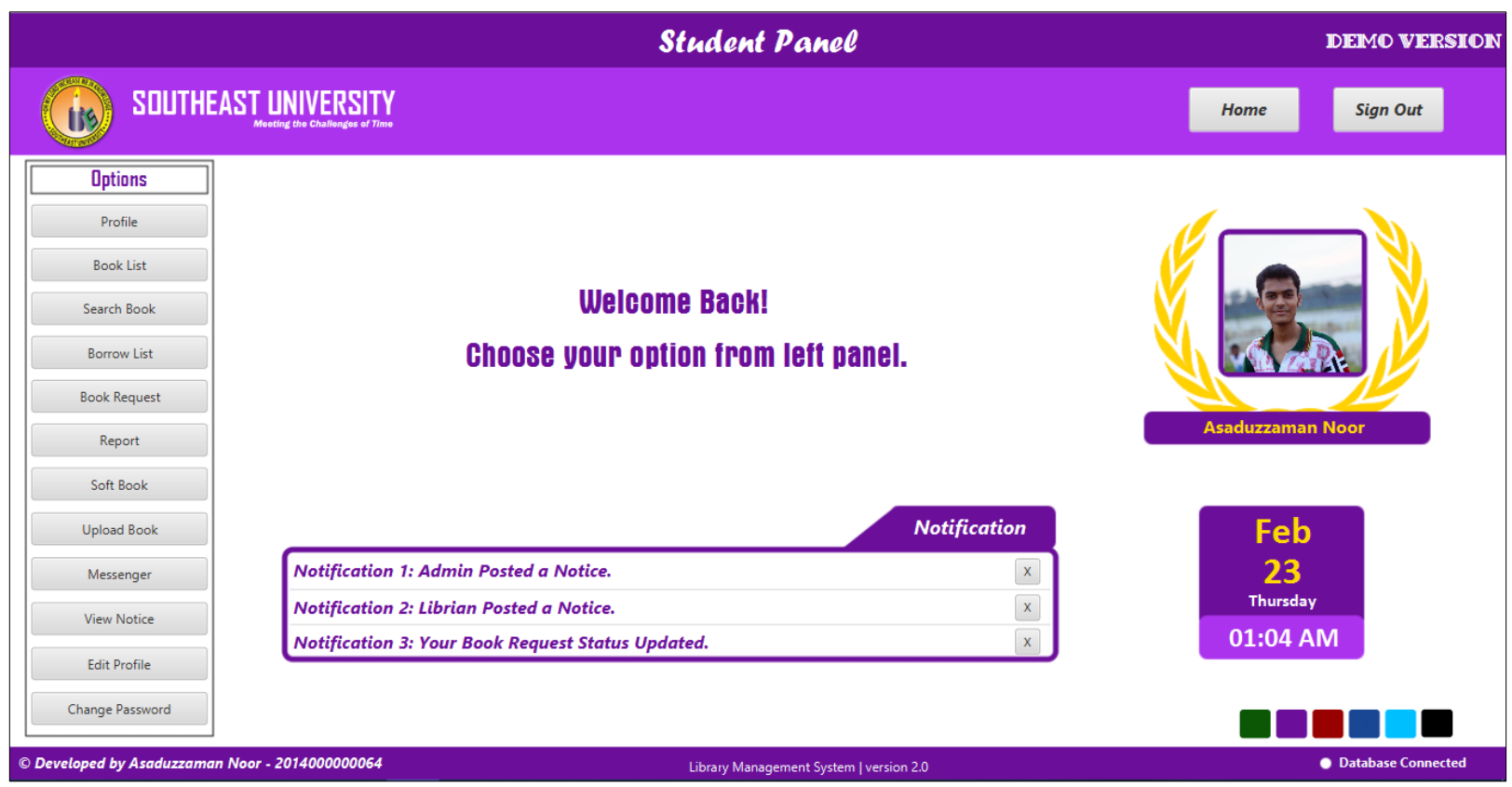

Fig. 12. Student Panel

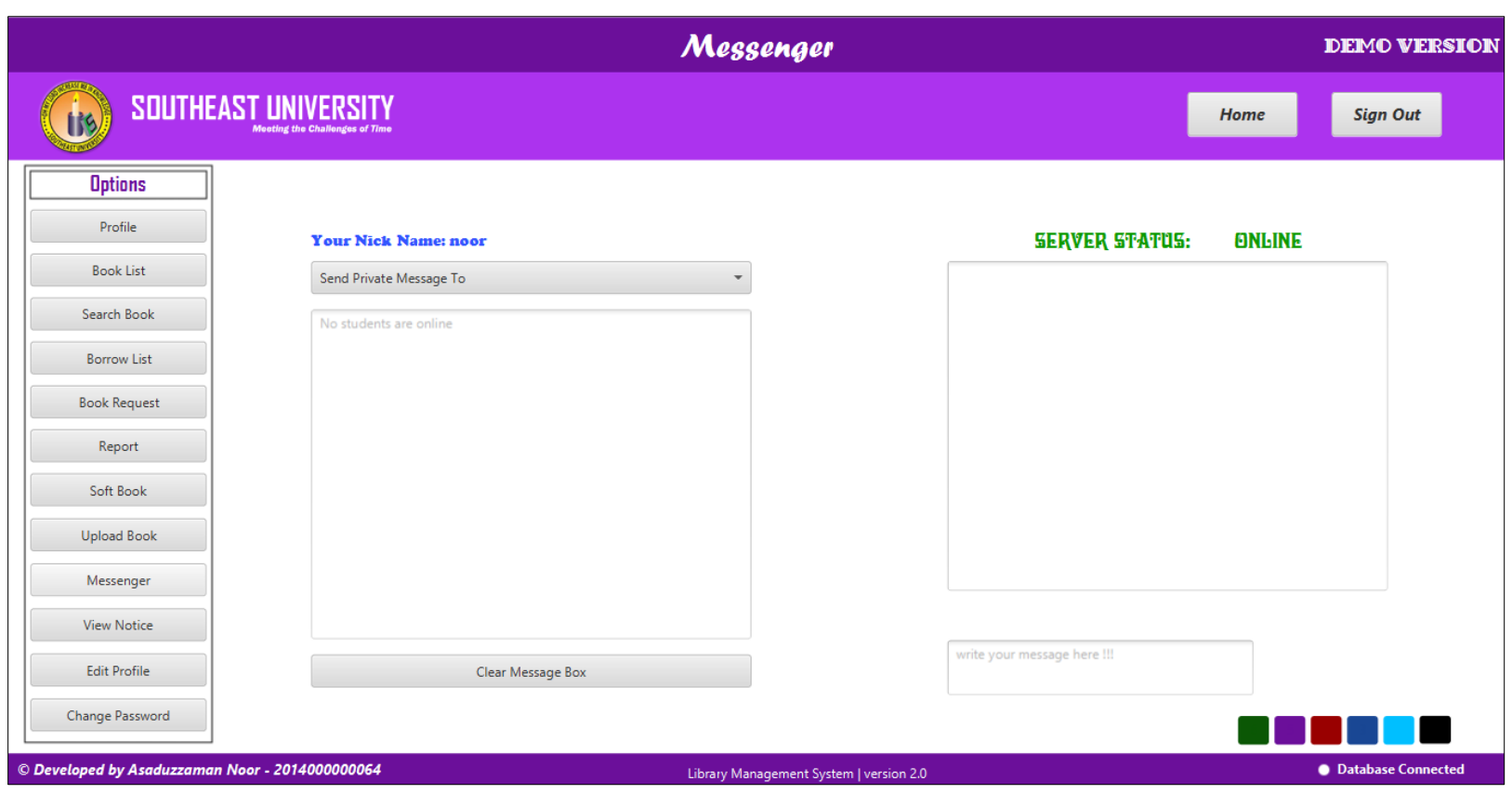

Fig. 13. Messenger

\subsection{Other View}

When a user enter wrong credentials, then he/she will see a red error. By clicking on "red error forgot password page", user could notice a notification, i.e., "Enter Valid Email Address". Pressing verify button, he/she could send an email with new password.

\section{CONCLUSION AND FUTURE WORKS}

In this paper, an online Java based user interactive database management system is successfully developed, which is much applicable to University libraries. Using this software any user without having any knowledge of Java could easily be able to understand the graphical reports of various transactions like availability of books, number of copies, fine etc. Proper security has also been maintained, so that only authorized users permitted by the Admin could access the services. This software can be run on any operating system having Java virtual machine. From a proper analysis of positive points and constraints, it can be concluded that this is a highly efficient GUI based software. This library management system is working properly and meeting to all user requirements according to the educational institutions.

In near future, mobile-based applications rather than web based and desktop, will be developed. Besides, this software will be extended by adding more features after getting feedbacks from the customers.

\section{REFERENCES}

[1] S. Fu, Y. Z., Seinminn, "Library Management System Based on Recommendation System," International Conference on Information Computing and Applications, Springer, Berlin, Heidelberg, pp 488-497, 2013. 
[2] J. M. Hellerstein, M. Stonebraker, J. Hamilton, "Architecture of a Database System," Journal Foundations and Trends in Databases, USA, Vol 1, Issue 2, pp 141-259, 2007.

[3] Y. Nie, "Digital Library Billing Management System Design and Implementation," Advanced Research on Electronic Commerce, Web Application, and Communication. Communications in Computer and Information Science, vol 143. Springer, Berlin, Heidelberg, pp 352-358, 2011.

[4] R. Salman, "Developing Multithreaded Database Application Using Java Tools and Oracle Database Management System in Intranet Environment," International Conference on Advanced Information Technologies and Applications, pp. 67-79, 2015.

[5] A. I. Wasserman, "Software Engineering Issues for Mobile Application Development," Workshop on Future of software engineering research, Santa Fe, New Mexico, USA, 2010.
[6] P. Deitel, and H. Deitel, "Java ${ }^{\mathrm{TM}}$ : How to program," $9^{\text {th }}$ Edition, Prentice Hall, 2015, ISBN 978-0-13-257566-9.

[7] H. Schildt, "Java ${ }^{\mathrm{TM}}$ : The complete reference," $9^{\text {th }}$ Edition, Oracle Press, 2015, ISBN: 978-0-07-180856-9.

[8] M. S. Hossen, and S. Ahmed, "Development of a Java based simulator for OFDM system," International Conference on Materials, Electronics and Information Engineering, Rajshahi University, Bangladesh, 2015.

[9] NetBeans, "https://netbeans.org/features/java/index.html".

[10] Y. T. Yang, J. C. S. Kumamoto, "Data Warehouse Applications in Libraries - The Development of Library Management Reports," IEEE International Congress on Advanced Applied Informatics, Japan, 2016.

[11] L. Mocean, V. P. Bresfelean, M. H. Macelaru, “A Proposa of an Academic Library Management System Based on an RDF Repository," International Conference on Business Information Systems, Springer, Cham, vol 263, 2017. 